\title{
THE TREATMENT OF UNSTABLE FRACTURE-DISLOCATIONS OF THE THORACO-LUMBAR SPINE ACCOMPANIED BY PARAPLEGIA
}

\author{
J. Lewis and B. McKibBin, CARDifF, WaLES
}

The work of Nicoll (1949) and of Holdsworth and Hardy (1953) made it possible to define an injury to the thoraco-lumbar spine characterised by rupture of the posterior ligament complex, instability, and a high incidence of neurological damage. The treatment of these injuries remains controversial and practice varies in different parts of the world. In Britain neither decompressive laminectomy nor manipulative reduction has achieved wide acceptance, and opinion has tended to polarise around contrasting alternatives.

The first of these is essentially conservative (Guttmann 1954, 1965, 1969). Primary consideration is given to the prevention and management of the neurological complications, and while it is recognised that the fracture of the spine, like any other, must be reduced and immobilised, this is achieved by postural means. By the skilful use of pillows and packs the force of gravity is exploited to reduce the deformity and immobilise the spine of the recumbent patient.

The other approach was suggested by Holdsworth and Hardy in 1953. They argued that neurological recovery could best be facilitated by rapid restoration of normal spinal alignment and stabilisation of the fracture, and recommended early open reduction and internal fixation. They also claimed that this method made nursing less difficult and improved the ultimate function of the spine.

Support exists for both these schools of thought and is sometimes expressed with great conviction; it is unlikely however that the relative merits of the two methods will ever be adequately appreciated unless they can be directly compared in a series of unselected cases. The present study represents such an attempt.

The cases were collected from two spinal injury units in Cardiff. In one, a policy of routine open reduction and plating of all unstable thoraco-lumbar spines was pursued, while the other was equally committed to postural reduction and non-operative methods. It is believed that the distribution of cases between these two units was on a random basis and that the study, although retrospective, allows a valid comparison of the methods to be made.

\section{CLINICAL MATERIAL}

The case histories and radiographs of all the patients who had been admitted to the two spinal injury units in a period of twenty-seven years were examined. In many instances these records were incomplete and such cases were excluded. In order to ensure that all cases included in both the surgically and conservatively treated groups were truly of the unstable type described by Holdsworth and Hardy (1953), the initial radiographs were examined without knowledge of the treatment that had subsequently been done. Only those cases which showed undoubted radiographic evidence of posterior ligamentous rupture were included. There was thus a possible total of ninety-three patients, of whom sixty-four had been operated upon while twenty-nine had been treated conservatively. As might be expected in such a long-term review, eighteen of the patients had died, seven in the conservative group. Eleven patients could not be traced and a further twenty-one could not, or would not, attend for examination. These exclusions left a final total of forty-three patients. All were male and their ages at the time of injury ranged from eleven to sixty-nine years. The circumstances of the accidents are shown in Table I. There were associated injuries in sixteen patients, of whom eight had had rib fractures and four had had concussion. As in most reported series, the commonest level of vertebral injury was at the thoraco-lumbar junction (51 per 
cent); the complete distribution is shown in Table II. In forty of the forty-three cases the neurological state at the time of admission had been well documented. In twenty-one the lesion was complete at the level of the vertebral injury, and in twelve the sacral cord lesion was complete but there was some degree of lumbar root sparing. Three cases had incomplete spinal cord lesions with spared roots and four showed root lesions only.

TABLE I

Circumstances OF INJURY

\begin{tabular}{|lcc|}
\hline \multicolumn{1}{|c}{ Mode of injury } & $\begin{array}{c}\text { Number of } \\
\text { cases }\end{array}$ \\
\cline { 1 - 1 } Coal mining accidents. & & 23 \\
Fall from height . & & 7 \\
Weights falling on back & 6 \\
Road traffic accidents . & 4 \\
Tractor overturning . & 2 \\
Crush by conveyor belt & 1 \\
\hline
\end{tabular}

TABLE II

LEVEL OF BONY LESION

\begin{tabular}{|lc|}
\hline Level & $\begin{array}{c}\text { Number of } \\
\text { cases }\end{array}$ \\
\cline { 3 - 3 } T.11-T.12 & 13 \\
T.12-L.1 & 22 \\
L.1-L.2 & 4 \\
L.2-L.3 & 1 \\
L.3-L.4 & 2 \\
L.4-L.5 & 1 \\
\hline
\end{tabular}

TABLE III

Methods of TREATMENT

\begin{tabular}{|c|c|}
\hline Method of treatment & Number of cases \\
\hline Posturing on plaster bed . & 2 \\
\hline Conservative postural reduction & 12 \\
\hline Operation $\quad . \quad . \quad . \quad$. & $\begin{array}{l}29 \\
\text { ( } 27 \text { spines plated) }\end{array}$ \\
\hline
\end{tabular}

TABLE IV

SURGical RedUCtION AND FiXation IN TWENTY-SEVEn CASES

\begin{tabular}{|llr|}
\hline Reduction & Excellent & 24 \\
& Incomplete & 3 \\
Fixation & Excellent & 22 \\
& Moderate & 4 \\
& Poor & 1 \\
\hline
\end{tabular}

METHODS OF TREATMENT

The breakdown of the cases in relation to the method of treatment is set out in Table III. In the patients treated conservatively postural reduction with pillows and packs was carried out in all but two. These had been treated in 1945 and 1950 on plaster beds before the dangers of this method had been fully realised. They were reviewed separately and the results have been presented only as a matter of historical interest. The average time of total confinement to bed for postured cases was thirteen weeks. The two patients treated on plaster beds had remained recumbent for twelve and twenty-five weeks.

In the patients treated surgically the spine was explored and a rupture of the interspinous ligament was confirmed. In two patients internal fixation proved to be impossible. One was a boy of eleven in whom the spinous processes were too small; in the other, unexpected 
fractures of the spinous processes were found. These cases were excluded, leaving a total of twenty-seven patients with internal fixation.

Williams (1963) plates were used for all internal fixations except one, in which Wilson plates were used (Wilson and Straub 1952). Fourteen patients had been operated upon by one surgeon and the remaining fifteen were distributed among ten other surgeons. The average time between injury and operation was fourteen hours and in no case did it exceed three days. The average period of total confinement to bed after operation was twelve weeks, the shortest being six weeks.

TABLE V

COMPLiCATIONS

\begin{tabular}{|c|c|c|c|}
\hline Plaster bed ( 2 cases) & Postured (12 cases) & Plated (27 cases) & \\
\hline \multirow{3}{*}{$\begin{array}{l}\text { Multiple pressure sores } \\
\text { in both cases }\end{array}$} & \multirow{3}{*}{ Nil } & Deep vein thrombosis & 1 \\
\hline & & Myocardial infarct & 1 \\
\hline & & Removal of plates & 9 \\
\hline
\end{tabular}

TABLE VI

Reasons for Removal of Plates

\begin{tabular}{|c|c|c|}
\hline Reasons for removal & $\begin{array}{l}\text { Number of } \\
\text { cases }\end{array}$ & $\begin{array}{c}\text { Time after operation } \\
\text { when plates } \\
\text { were removed }\end{array}$ \\
\hline Deep sepsis & 1 & 16 weeks \\
\hline Loose bolts and pain & 3 & $\begin{array}{l}11 \text { weeks } \\
16 \text { weeks } \\
40 \text { weeks }\end{array}$ \\
\hline Broken plates causing pain & 2 & $\begin{array}{l}5 \text { years } \\
8 \text { years }\end{array}$ \\
\hline Loose bolts but no pain & 3 & $\begin{array}{l}16 \text { weeks } \\
25 \text { weeks } \\
18 \text { months }\end{array}$ \\
\hline
\end{tabular}

\section{INITIAL ASSESSMENT}

The degree of initial kyphosis was measured on the earliest radiographs by the method illustrated in Figure 1. Forward displacement was estimated as a proportion of the anteroposterior diameter of a vertebral body. In the series treated conservatively only one patient had initial displacement greater than one-third of a vertebral body, whereas in the series in which plating was undertaken there were five such cases.

In the patients operated upon the success of surgical reduction and fixation was assessed from the radiographs taken within twenty-four hours of operation: the results are shown in Table IV. Reduction was considered to be excellent if there was no forward displacement and only slight residual kyphosis. Reduction was incomplete in three cases, but displacement was never more than one-third of the diameter of a vertebral body. Fixation was considered to be excellent when the bolts could be seen to pass securely through the spinous processes of at least two vertebrae above and below the level of the dislocation. Fixation was considered to be moderate when there were either two bolts above and one below, or one bolt above and two below the level of the lesion. Fixation was poor when there was only one bolt above and one below the lesion. An example of satisfactory reduction and fixation is shown in Figures 2 and 3, which are of radiographs two and a half years after operation.

VOL. 56 B, NO. 4, NOVEMBER 1974 


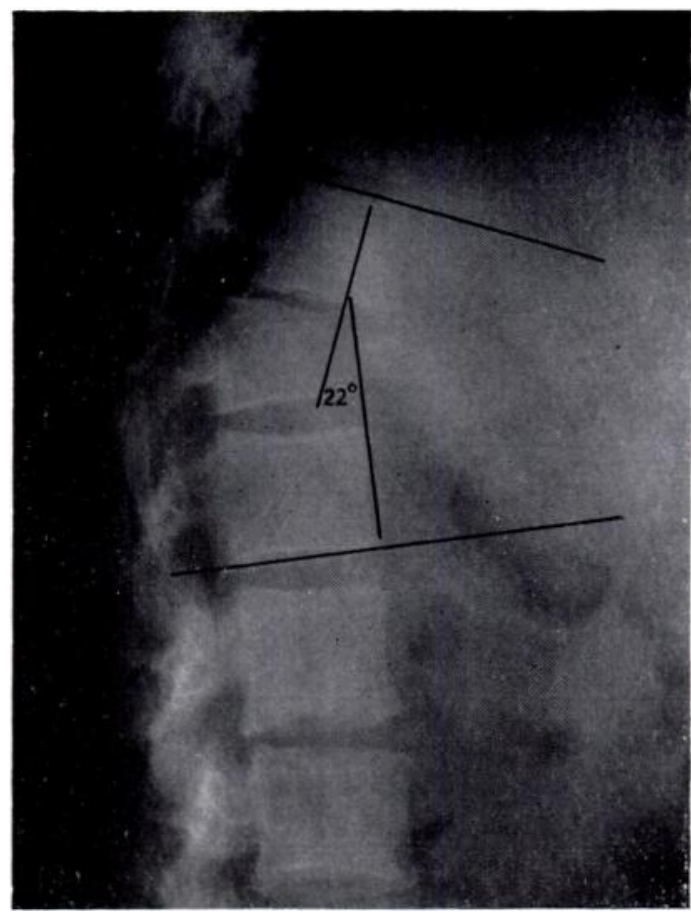

Fig. 1

Radiograph of a fracture-dislocation of T.11 on T.12. The position before treatment and showing the method of measuring the angulation.

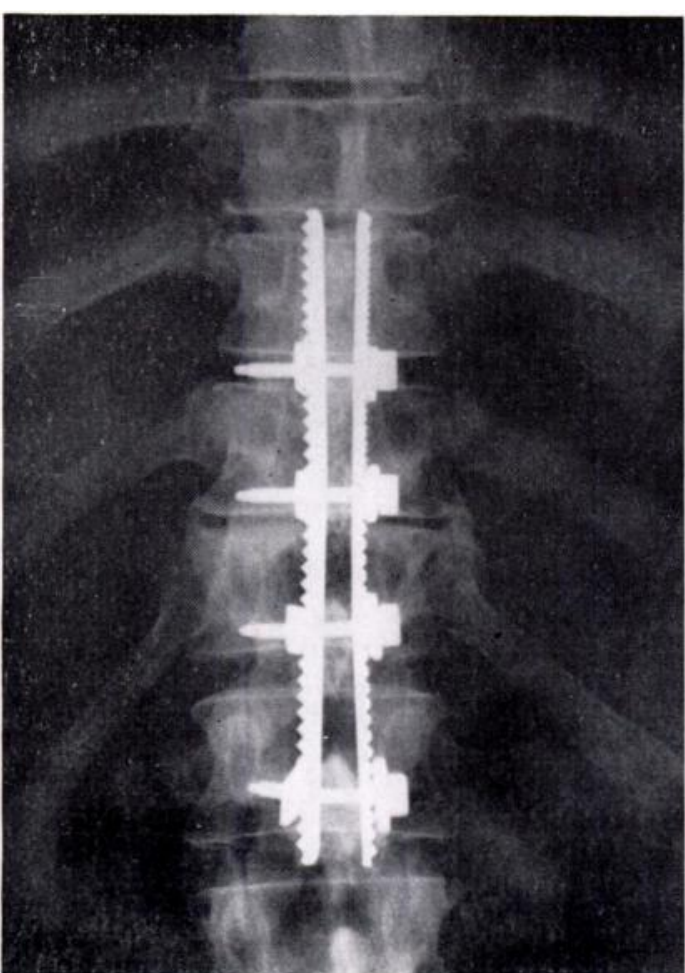

Fig. 2

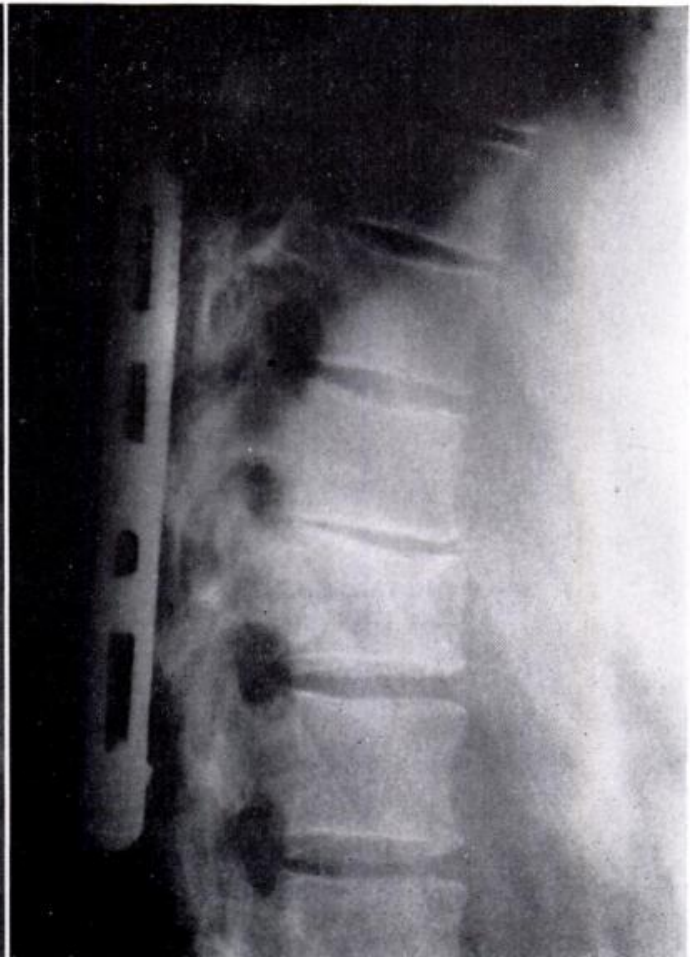

FIG. 3

Antero-posterior and lateral radiographs of a fracture-dislocation of T.11 on T.12, taken two years and six months after operation.

THE JOURNAL OF BONE AND JOINT SURGERY 


\section{COMPLICATIONS}

The complications of all forms of treatment are shown in Table $\mathrm{V}$.

The removal of plates in nine cases ( 33 per cent) was further examined and the reasons for removal are given in Table VI.

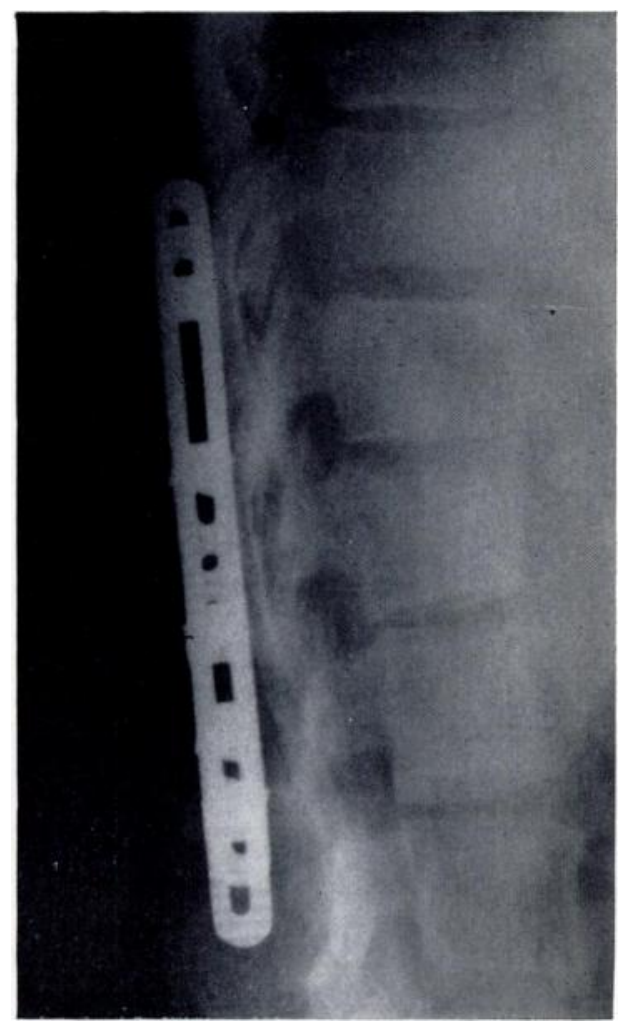

Fig. 4

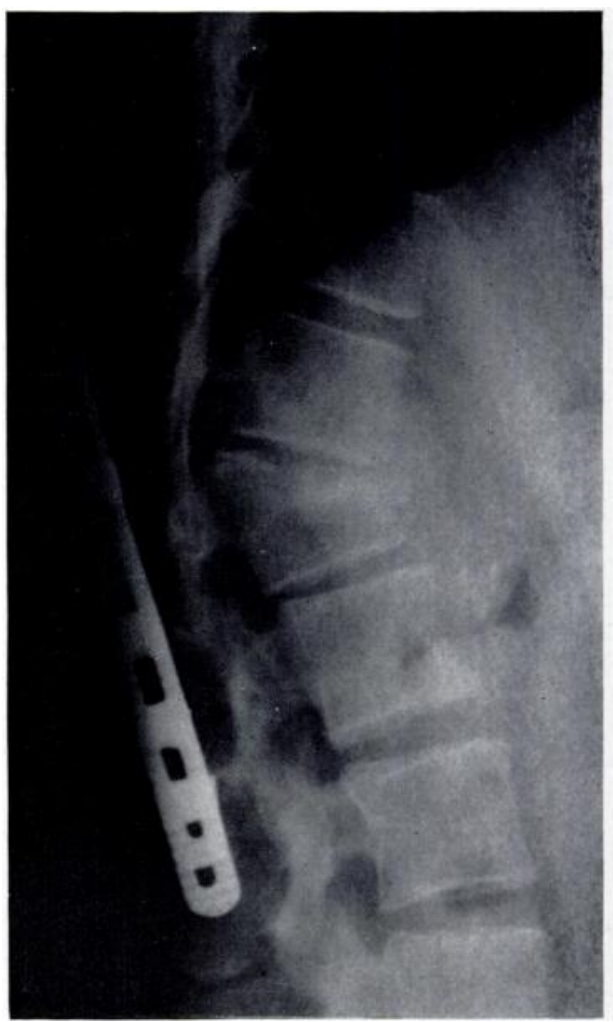

FIG. 5

Figure 4-Radiograph of a fracture-dislocation of T.12 on L.1. The position after plating shows satisfactory reduction and fixation. Figure 5-A radiograph showing the position nine months after operation and early mobilisation.

In the single case of deep sepsis the infection was not manifest until fourteen weeks after operation. Removal of the plates caused no deterioration of the reduction. In two of the cases with loose bolts associated with pain, the patients had been allowed to sit out of bed six weeks after operation. The initial radiographs showed excellent reduction and fixation soon after operation (Fig. 4) but by nine months the upper bolts had cut out, with resulting displacement (Fig. 5). In the two patients with fractured plates, pain was late in onset and obviously related to the fractures of the plates. In the three patients with loose bolts but no pain, the discovery was made on routine intravenous pyelography. It is possible that these plates need not have been removed.

\section{ASSESSMENT OF LATE RESULTS}

All patients were interviewed and examined. The shortest follow-up was one year and the longest twenty-seven years. The average duration of follow-up in the patients treated conservatively was seven and a half years and in those treated by operation nine years. The two patients treated on plaster beds were assessed after twenty-two years and twentyseven years. 
Special attention was paid to spinal symptoms, spinal function and evidence of neurological recovery.

Pain-All patients were questioned about spinal pain. Three grades were recognised: aching pain was classified as pain causing no distress and not requiring analgesics; moderate pain was pain requiring and usually relieved by analgesics; and severe pain was pain that could not be completely relieved by analgesics. The patients with severe or moderate pain all complained that pain disturbed their sleep and was related to posture. It was aggravated by prolonged standing or sitting, and partly relieved by lying. The analgesics used by these patients included pentazocine and dihydrocodeine.

TABLE VII

INCIDENCE OF SPINAL PAIN

\begin{tabular}{|c|c|c|c|}
\hline & $\begin{array}{c}\text { Plated } \\
\text { (27 cases) }\end{array}$ & $\begin{array}{l}\text { Postured } \\
\text { (12 cases) }\end{array}$ & $\begin{array}{l}\text { Plaster bed } \\
\text { ( } 2 \text { cases) }\end{array}$ \\
\hline No pain & 22 & 4 & 1 \\
\hline Aching pain & 5 & 5 & 0 \\
\hline Moderate pain & 0 & 1 & 1 \\
\hline Severe pain & 0 & 2 & 0 \\
\hline
\end{tabular}

TABLE VIII

Radiological ObServations

\begin{tabular}{|lccc|}
\hline & $\begin{array}{c}\text { Plated } \\
\text { (27 cases) }\end{array}$ & $\begin{array}{c}\text { Postured } \\
\text { (12 cases) }\end{array}$ & $\begin{array}{c}\text { Plaster bed } \\
\text { (2 cases) }\end{array}$ \\
\cline { 1 - 4 } Kyphosis & 12 & 6 & 0 \\
Moderate (20-40 degrees) & 2 & 3 & 0 \\
$\begin{array}{l}\text { Severe (over 40 degrees) } \\
\text { Forward displacement }\end{array}$ & 0 & 3 & 0 \\
Over one-third diameter & 0 & & 0 \\
\hline
\end{tabular}

The incidence of pain in the three groups is shown in Table VII, where it can be seen that all of the patients with significant pain were in the group treated conservatively. A few patients complained of vague aches in the legs but no patient was found to have significant root pain in legs or buttocks.

Clinical deformity-Examination of the spine revealed a moderate or severe gibbus in three patients treated conservatively. They all had moderate or severe pain. A moderate gibbus was found in one patient treated by plating. Scoliosis was evident in only one patient, who had been treated on a plaster bed. No patient had problems with skin breakdown over the gibbus, but in two cases in the conservatively treated group there was definite tenderness over the deformed spine. Neither of these patients could sit in a hard-back upright chair because of pain. No patient complained of stiffness of the spine.

Radiological assessment-The radiographs at the time of review were examined and the amounts of kyphosis and forward displacement measured. The findings are shown in Table VIII. The average kyphosis in the plated spines was 20 degrees compared with 29 degrees in the group treated conservatively which also included the only examples of severe forward slipping.

Examples of severe deformity in the conservatively treated group are shown in Figures 6 to 8. The radiographs in Figure 6 are of a patient treated conservatively for thirteen weeks. 
There is a kyphosis of 50 degrees and appreciable forward displacement. This patient had severe spinal pain. The case illustrated in Figure 7 is of a patient with severe pain treated conservatively for twenty-one weeks. There was kyphosis of 45 degrees, with marked forward displacement. The patient whose radiograph is shown in Figure 8 had been treated conservatively for fourteen weeks. There was kyphosis of 41 degrees and forward displacement. The patient had moderate spinal pain.

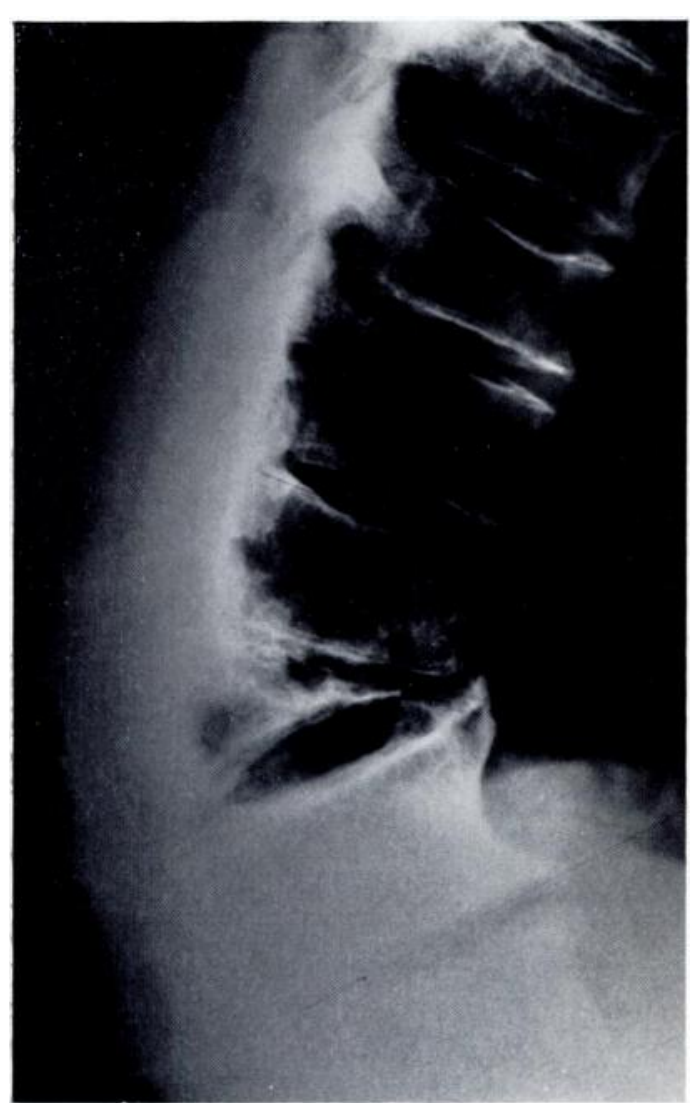

FIG. 6

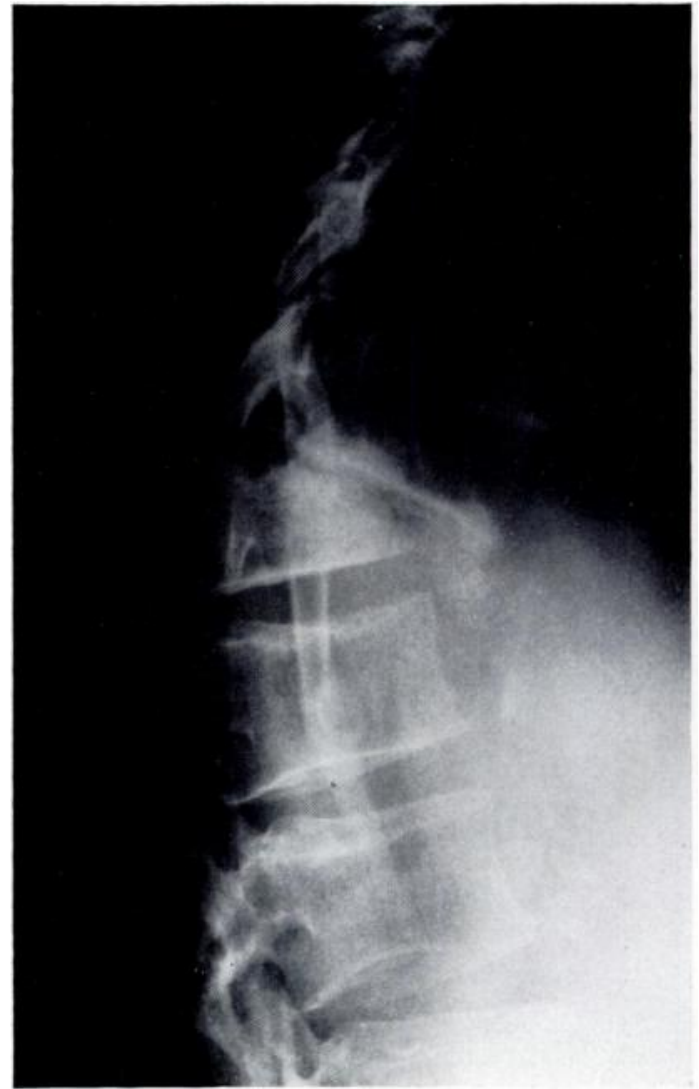

Fig. 7

Figure 6-A fracture-dislocation of T.12 on L.1. This radiograph was taken six years after conservative treatment. Figure 7-A radiograph two years and four months after conservative treatment of a fracture dislocation of T.11 on T.12.

Anterior interbody fusion occurred in eight patients treated conservatively (67 per cent) and in seventeen patients treated by plating ( 63 per cent). It also occurred in both the patients treated on plaster beds.

The only spine with appreciable lateral displacement and angulation is shown in Figure 9. This patient had been treated on a plaster bed for twenty-five weeks. Despite many years of freedom from pain this patient was, at the time of review, complaining of moderate spinal pain.

Neurological assessment-The neurological pattern at the time of review was compared with that which had been recorded at the initial examination in the forty cases which had been well documented in this respect. Some degree of recovery was noted in five out of twelve patients treated conservatively and in ten out of twenty-six treated by plating. In some patients the improvement amounted to no more than one spinal segment and may therefore represent only an error in the initial assessment. No patient had evidence of deterioration. 


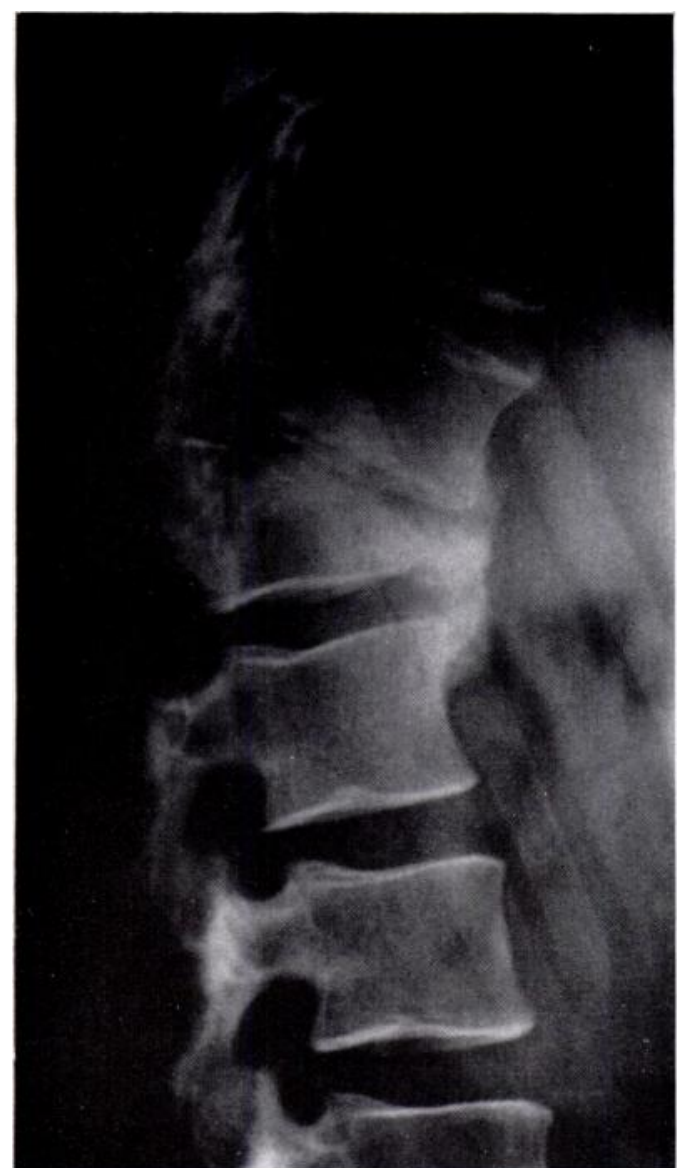

FIG. 8

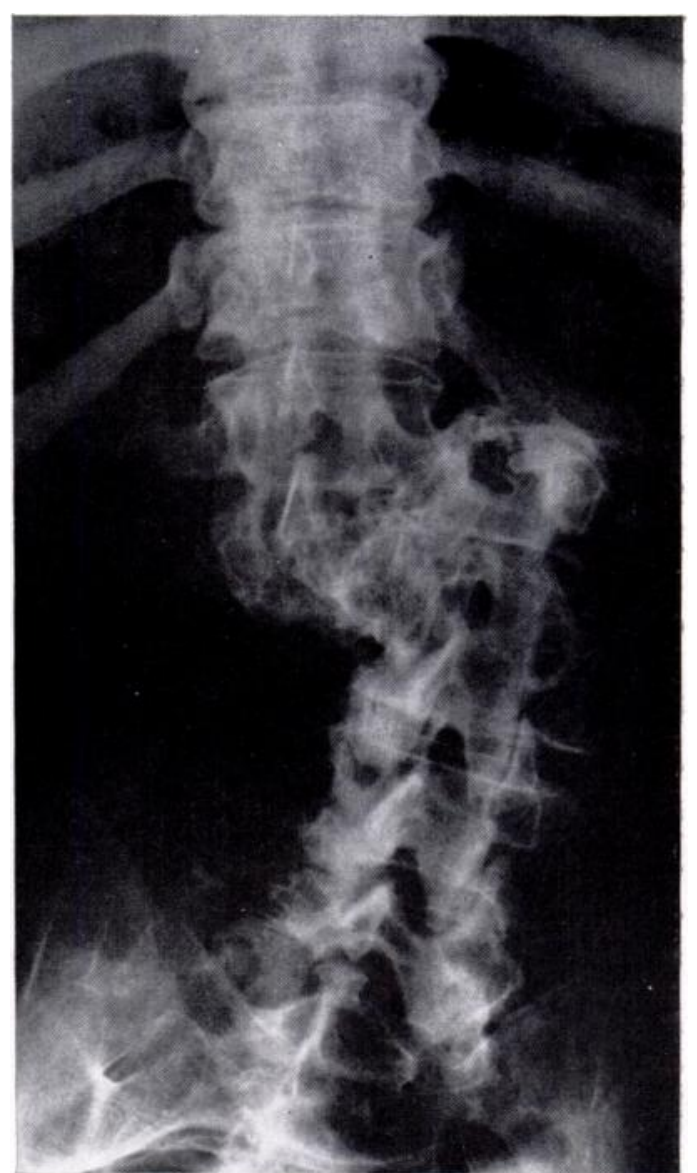

FIG. 9

Figure 8-A radiograph one year and seven months after conservative treatment of a fracture-dislocation of T.12 on L.1. Figure 9-A radiograph showing a fracture-dislocation of L.1 on L.2 twenty-five years after conservative treatment.

\section{DISCUSSION}

In the light of these comparative results it is possible to review some of the arguments that have been put forward in relation to the two methods of treatment under discussion.

The most important claim by Holdsworth and Hardy (1953) on behalf of internal fixation was that neurological recovery was facilitated. This is extremely difficult to prove. It is impossible to prove in an individual case, and since the overall recovery rates are so low a much larger comparative series than the one reported here will be required to have any statistical significance. Such a study should preferably be prospective.

Some degree of recovery did occur in just over one-third of our patients, and on the evidence available it did not appear to be influenced by treatment. These findings are comparable with the results published in other non-comparative series, whether treated by operative methods (Holdsworth and Hardy 1953) or by non-operative methods (Frankel, Hancock, Hyslop, Melzak, Michaelis, Ungar, Vernon and Walsh 1969) and they compare favourably with some reports of the results from laminectomy (Kaufer and Hayes 1966). The consistency of these rates, in spite of widely different methods of treatment, lends support to Guttmann's (1969) belief that the most important factor determining neurological recovery is the damage sustained by the nervous tissue at the time of the accident, rather than the anatomical circumstances in which it subsequently finds itself. This leads to the gloomy conclusion that the best one can do for the nervous tissue is to prevent further damage. 
Holdsworth's (1953) claim that nursing of the patient is facilitated by plating cannot be assessed in a retrospective review of this type, but for his further contention that spinal function is improved there is undoubted support. None of the patients so treated had any significant complaint of symptoms in the back, whereas in the much smaller conservative series there were several patients who were seriously disturbed by pain. In two cases it is noteworthy that the patient had enjoyed several years of freedom from pain, suggesting that secondary degenerative changes were responsible. Nicoll (1949) has shown that in the short term there may not be a very close relationship between spinal deformity and symptoms, but the present results suggest that given sufficient time such a relationship may well come about.

The most serious criticism that has been made of open reduction and plating is that the operation fails to do what it sets out to do. Guttmann (1969) stated that a certain amount of forward collapse is inevitable in these injuries, possibly due to avascular changes in the vertebral bodies, and that to attempt to restrain this with a posterior plate is futile. This is a most damaging allegation; if plating does not succeed in maintaining the position of the spine then most of the arguments in its favour collapse. Our study has shown that the criticism is only technically valid. Some forward angulation did occur in spite. of the plates but to a much lesser extent than in the other groups. In practical terms plating appears to have restrained the forward angulation and displacement to the point where it did not interfere with function even in the long term, and its use therefore appears to be justified on these grounds alone.

Further criticism of plating has been occasioned by the surgical complications which their use entails. Guttmann (1969) dealt particularly severely with the Williams plate on the grounds that it is a cause of stiffness. Such a finding would be unexpected on theoretical grounds following the immobilisation of only three lumbar joint levels, and no such stiffness was noted in this series. The necessity for removal of the plate at a second operation because of loosening or breakage has also been raised as a criticism; removal was in fact required in a third of the cases. It seems, however, from the measurement of deformity that the plate had already fulfilled its function by the time removal was required.

It may be concluded, therefore, from the results of this comparative series that the balance of evidence is in favour of plating as opposed to conservative treatment, at least in those cases with significant displacement. The results are consistent with the findings of Frankel et al. (1969) in a much larger conservative series that conservative measures often fail to reduce the displacement if it is initially greater than half the diameter of a vertebral body, and they show that such failure of reduction may ultimately give rise to symptoms.

However, although our findings appear to vindicate the claims of Holdsworth and Hardy (1953), the emphasis in the argument is different. It has not been possible to show that early open reduction and internal fixation improve the chances of neurological recovery, and this controversy remains unresolved. Instead, the argument hinges on the reduction of pain and deformity in the spine itself. This is a less dramatic achievement than a reduction in the paralysis, but is nevertheless a worthwhile aim. A paraplegic patient can well do without a painful deformed back to add to his misery.

Not all previous accounts of plating have given such satisfactory results. Roberts (1969) reported a series in which there was a high incidence of infection, failure of fixation and recurrence of deformity. However, a detailed comparison of his results with the present series shows that in the former the standard of technical surgery, especially with regard to firmness of fixation, was lower. In addition, many of the patients had been kept in bed for much shorter periods. The increase in deformity after plating which occurred in the few patients in this series who were mobilised early confirms that internal fixation can be regarded as no more than an adjunct to immobilisation, and that the patients must stay in bed for at least twelve weeks. A further point of difference is that in the present series all the patients had been treated in a specialist unit, whereas in the earlier series many had been operated

VOL. 56 B, NO. 4, NOVEMBER 1974 
upon by surgeons in general hospitals. Although Holdsworth (1963) believed that the method could be readily applied in any accident unit, we are unable to refute Roberts's (1969) conclusion that the level of failure outside special units is unacceptable.

What treatment, then, should be offered to the patient with an unstable fracture without significant displacement? Such fractures remain liable to further angulation, and indeed in our conservative series some of the most deformed spines at the time of review showed very little primary displacement. On this basis it could be argued that all should be plated, but it must be remembered that there were some perfectly satisfactory results from conservative management. The only way to select patients for operation seems to be on the basis of a trial of conservative treatment with close radiological scrutiny. Any tendency for the spine to deform on this regime would constitute an indication for delayed plating. The final decision in these cases will often depend on the degree of experience on the part of the surgeon and on the quality of the nursing staff which he has at his command.

\section{SUMMARY}

1. The results of treatment have been compared in two unselected series of patients with unstable fractures of the thoraco-lumbar spine accompanied by paraplegia.

2. One group had been treated by conservative or "postural" methods while the others had been subjected to open reduction and internal fixation with double plates.

3. No difference in the amount of neurological recovery could be detected between the two groups but while a number of conservatively treated patients had significant residual spinal deformity and subsequently developed serious pain, this did not occur in any of the patients treated by plating.

4. It is concluded that open reduction and internal fixation are indicated in displaced fractures in the interests of long-term spinal function.

We are indebted to the Clinical Research Committee of the Welsh Hospital Board for the financial assistance with this investigation and to Dr D. Ferguson Lewis of Rookwood Hospital, Cardiff, for invaluable help in tracing the patients and providing accommodation.

\section{REFERENCES}

Frankel, H. L., Hancock, D. O., Hyslop, G., Melzak, J., Michaelis, L. S., Ungar, G. H., Vernon, J. D. S., and WALSH, J. J. (1969): The value of postural reduction in the initial management of closed injuries of the spine with paraplegia and tetraplegia. Paraplegia, 7, 179-192.

Guttmann, L. (1954): Initial treatment of traumatic paraplegia. Proceedings of the Royal Society of Medicine, 47, 1103-1109.

GutTMAnN, L. (1965): Initial treatment of traumatic paraplegia and tetraplegia. In Spinal Injuries. Proceedings of a symposium held in the Royal College of Surgeons of Edinburgh, June 7 and 8, 1963, pp. 80-92. Ed. P. Harris. Edinburgh: Royal College of Surgeons.

GutTMANN, L. (1969): Spinal deformities in traumatic paraplegics and tetraplegics following surgical procedures. Paraplegia, 7, 38-49.

Holdsworth, F. W. (1963): Fractures, dislocations and fracture-dislocations of the spine. Journal of Bone and Joint Surgery, 45-B, 6-20.

HoldSWORTH, F. W., and HARDY, A. (1953): Early treatment of paraplegia from fractures of the thoraco-lumbar spine. Journal of Bone and Joint Surgery, 35-B, 540-550.

KAUfER, H., and HAYES, J. T. (1966): Lumbar fracture-dislocation. Journal of Bone and Joint Surgery, 48-A, 712-730.

Nicoll, E. A. (1949): Fractures of the dorso-lumbar spine. Journal of Bone and Joint Surgery, 31-B, 376-394.

RoberTs, P. H. (1969): Internal metallic splintage in the treatment of traumatic paraplegia. Injury, 1, 4-11.

Williams, E. W. M. (1963): Traumatic paraplegia. In Recent Advances in the Surgery of Trauma, Chapter 13, pp. 171-186. Edited by D. N. Matthews. London: J. \& A. Churchill Ltd.

Wilson, P. D., and Straub, L. R. (1952): Lumbosacral fusion with metallic-plate fixation. American Academy of Orthopaedic Surgeons Instructional Course Lectures, Volume IX pp, 53-57. Ann Arbor: J. W. Edwards. 